\title{
The effect of sports shoes on flat foot
}

\author{
Korkmaz M.F. ${ }^{1 \mathrm{ABCDE}}$, Acak M. ${ }^{2 \mathrm{ABCDE}}$, Duz S. ${ }^{2 \mathrm{ABCDE}}$ \\ ${ }^{1}$ Department of Orthopedics and Traumatology, Faculty of Medicine, Istanbul Medeniyet University, Istanbul, Turkey \\ ${ }^{2}$ Faculty of Sports Science, Inonu University, Malatya, Turkey
}

Authors' contributions: A - Study design; B - Data collection; C - Statistical analysis; D - Manuscript Preparation; E - Funds Collection.

\begin{abstract}
Purpose:

This study was conducted to determine the effects of participation in sports on the structural deformities of the foot.

Material:

A total of 2013 athletes (1301 males, 712 females) who had regularly participated in sports for a minimum of three years were included in the study. Screening of the sole was performed using a podoscope as it is a reliable and practical device. The structure of the sole was evaluated with the highly valid Staheli index.

Results: A significant relationship was detected between the ages of the athletes, years in sport, branch of sports variables and the prevalence of flat foot. However, no significant relationship was found between the athletes' gender and the prevalence of flat foot.

Conclusions: It is thought that the training regimes, the floor on which the sports is performed and the shoes used in sports had effects on flat foot deformity. Based on our results, we assert that redesigning the competition shoes and using sports shoes with arch support during warm-ups, running and other sportive and educational drills outside the routine activities of the sports branch may be beneficial for foot health.

Keywords: branch of sports, flat foot, pes planus, sports shoes.
\end{abstract}

\section{Introduction}

The foot is an important organ in our body that bears the entire weight of the body, initiates the chain of motion, forms a support base for an upright posture of the body and is the most mechanically forced limb [1]. Therefore, structural and biomechanical problems of the foot are the key factors in determining the functions of the lower extremities and the etiology of recurring injuries [2, 3].

Several studies regarding the analysis and evaluation of the footprint can be found in the literature [4-6]. Flat foot deformity, also known as pes planus, is usually described as a decrease in the height or loss of the medial longitudinal arch (MLA) or as the malalignment of the hindfoot (hindfoot valgus) [4]. Although the prevalence of the disorder increases with the loosening of the ligaments in the foot, not all flat foot deformities are the same [7]. Therefore, in diagnosing the disorder, assessment of the loss of height in the MLA $[8,9]$, clinical examination [10], ultrasonography [11], somatometric measurements [12], inked or digital foot printing [4], pedobarography [9] and photographic imaging [13] techniques are used. Individuals with flat foot deformity are more susceptible to foot and knee pain, stress fractures, foot injuries and low performance while exercising [14]. Such occurrences are more evident among athletes as the repetitive movements used in competitive sports exerts a higher load on the feet than usual $[15,16]$. Although participation in sports leads to musculoskeletal adaptations and results in significant changes in the structure and plantar pressures of the foot, the different athletic tasks performed in various sports may have an impact on the injury risk factors [17].

Previous studies reported significant differences between plantar pressure patterns of athletes and nonathletes when the playing surface and gender were taken into account [18-21]. However, studies investigating the

\footnotetext{
(c) Korkmaz M.F., Acak M., Duz S., 2020
}

doi:10.15561/26649837.2020.0203 foot structure of the athletes are limited. Thus, the effects of different branches of sports on foot structure have not yet fully been understood. Therefore, a study with a population of athletes may provide information regarding age and gender-related differences and help to determine the effect of sports participation on the foot structure.

Consequently, the objective of this study was to investigate the effects of different branches of sports on the structure of the foot in amateur athletes.

We hypothesized that amateur athletes who participate in various sports are more likely to have structural foot disorders due to repetitive mechanical loads on the foot.

\section{Materials and Methods}

\section{Participants}

The study included a total of 2013 amateur athletes (1301 males, 712 females) who regularly participated in sports for a minimum of three years and who exercised at least three days a week. Individuals with foot disorders, open wounds, any co-existent musculoskeletal pathologies, concurrent use of in-shoe orthotics or a previous spinal/lower limb surgery were excluded. Demographic data of the participants including age, gender, years active in sport and branch of sports were recorded. Of the participants, 603 were wrestlers (536 males, 67 females), 259 were soccer players (133 males, 126 females), 146 were swimmers (98 males, 48 females), 146 were handball players ( 65 males, 81 females), 137 were boxers (114 males, 23 females), 125 were judo players ( 72 males, 53 females) and 56 were race-walkers (32 males, 24 females) (Table 1).

\section{Research Design}

Many methods have been used, such as the measurement of height loss in the medial longitudinal arch have been used in classification [22], the toe raise 'Jack' test or the Hubscher maneuver are most commonly used for the 
Table 1. Demographic data of the participants.

\begin{tabular}{|c|c|c|}
\hline Variable & $f$ & $\%$ \\
\hline \multicolumn{3}{|l|}{ Gender } \\
\hline Male & 1,301 & 64.6 \\
\hline Female & 712 & 35.4 \\
\hline Total & 2,013 & 100 \\
\hline \multicolumn{3}{|l|}{ Branch of sports } \\
\hline Wrestling (Freestyle) & 327 & 16.2 \\
\hline Wrestling (Greco-Roman) & 276 & 13.7 \\
\hline Soccer & 259 & 12.9 \\
\hline Taekwondo & 247 & 12.3 \\
\hline Volleyball & 160 & 7.9 \\
\hline Handball & 146 & 7.3 \\
\hline Swimming & 146 & 7.3 \\
\hline Boxing & 137 & 6.8 \\
\hline Basketball & 134 & 6.7 \\
\hline Judo & 125 & 6.2 \\
\hline Race-walking & 56 & 2.8 \\
\hline Total & 2,013 & 100 \\
\hline \multicolumn{3}{|l|}{ Age range } \\
\hline $14-18$ & 589 & 29.3 \\
\hline $19-24$ & 996 & 49.5 \\
\hline $25-29$ & 293 & 14.6 \\
\hline 30 and over & 135 & 6.7 \\
\hline Total & 2,013 & 100 \\
\hline \multicolumn{3}{|l|}{ Participation in sports } \\
\hline $3-5$ years & 441 & 21.9 \\
\hline $6-8$ years & 882 & 43.8 \\
\hline 9-11 years & 294 & 14.6 \\
\hline $12-14$ years & 212 & 10.5 \\
\hline 15 years and over & 184 & 9.1 \\
\hline Total & 2,013 & 100 \\
\hline
\end{tabular}

classification of the flat foot as 'flexible' or 'rigid' [23]. The footprint method, the second most common technique, calculates the ratio between the narrowest width of the foot arch and the widest width of the heel region [4, 6]. The use of a podoscope devise have made measurements and evaluation of the footprint more accurate and quicker to perform. This method accurately identifies pressure problems and is capable of offering visual information on disorders such as flat foot, high arch, excessive pronation, early detection of hallux valgus, hammertoes, etc. [24]. Compared with other devices, a podoscope also carries the advantage of increased visibility of the foot since the pressure point information is fused with the rest of the plantar surface [24]. Therefore, in the current study the relationship between the sole and the stepped-on surface was assessed using a podoscope (Chinesport S.p.a., Udine, Italy). In this method, the person stands stable on a glass surface and the image of the foot is reflected onto a mirror beneath it. The image is then recorded on the computer and the planimetric index values calculated with supreme precision to determine whether the foot arch is normal, cavus or flat $[3,6,24]$.

Informed consent was obtained from all participants and the study was approved by the Ethical Committee of Inonu University. All pre-measurement conditions such as the time spent between taking the shoes off and starting the test, the hardness of the surface stood on barefoot and the temperature of the test platform were identical for all participants. After thoroughly cleaning their soles with alcohol, the participants were asked to stand still in an upright normal orthostatic position on the podoscope and distribute their body weights equally on both feet. Their heads were positioned to look straight forward according to the Frankfurt plane.

The obtained image of the sole was analyzed using the Global Postural System/PODATA software. Generally, Staheli's plantar arch index (SI), Clarke's angle (CA) and the Chippaux-Smirak index (CSI) are used in analyzing the footprints. In our study, the structure of the sole was assessed using the highly valid SI [25]. The SI is the ratio obtained by dividing the narrowest width of the central foot to the widest width of the heel region (Fig. 1). The 
range between 0.50 and 0.70 was considered normal, whereas a ratio of over 0.70 was accepted as pes planus [4].
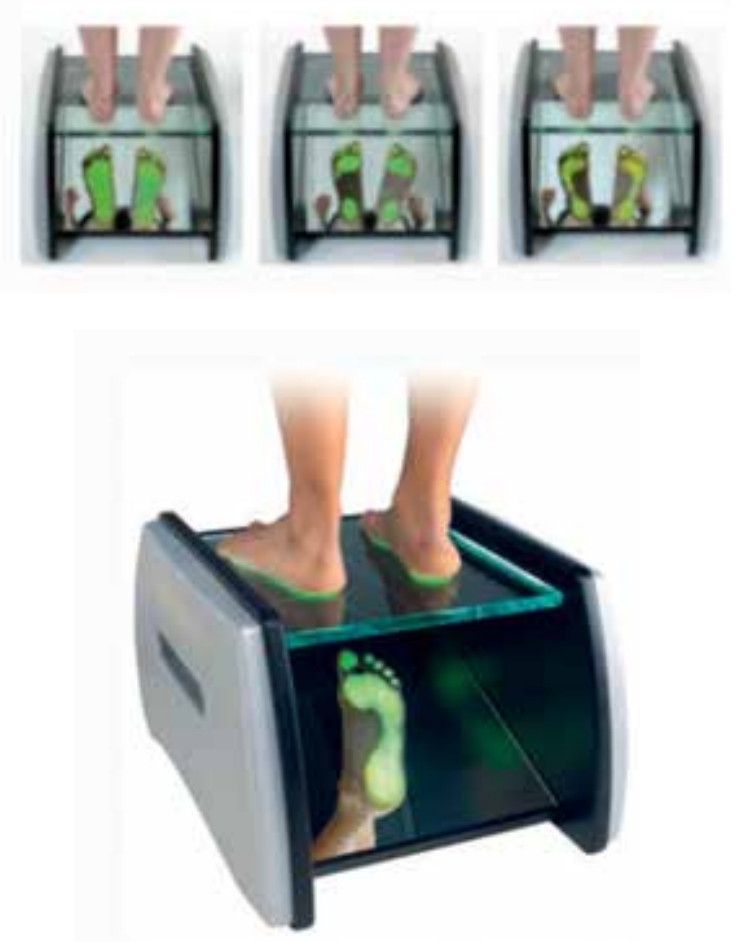

Fig. 1. The footprint method.

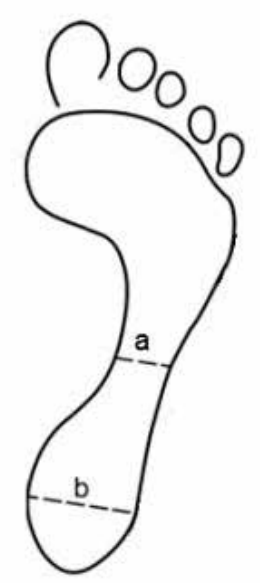

Fig. 2. Schematic representation of the regions of measurement in the calculation of the Staheli index ( $\mathrm{SI}=\mathrm{a} / \mathrm{b}$; $\mathrm{a}$ : the narrowest width of the central foot, $\mathrm{b}$ : widest width of the heel region).

\section{Statistical Analysis}

As the data did not show a normal distribution according to the Shapiro-Wilk test, non-parametric tests were applied. Associations between characteristics of the participants and prevalence of flat foot were analyzed using the chi-square test. All data were analyzed using the "IBM SPSS Statistics for Windows, (Version 21.0. Armonk, NY: IBM Corp.)" The level of significance was accepted as $\mathrm{p}<0.05$.

\section{Results}

Demographic characteristics of the participants are presented in Table 1. The prevalence of flat foot was $7.5 \%$ in the $14-18$ age range group, $12.9 \%$ in the $19-24$ age range group, $16.2 \%$ in the $25-29$ age range group and $19.1 \%$ in the 30 years and above age group. The results of the chi-square test revealed a significant relationship between the athletes' age and the prevalence of flat foot $\left(\chi_{(3)}^{2}=3.133, p<.05\right)$. In other words, the prevalence of flat foot increased as the age of the athletes increased (Table 2).

The prevalence of flat foot was $6.3 \%$ among the athletes who participated in sports for 3 to 5 years, $12.2 \%$ among those who participated in sports for 6 to 8 years, $15.6 \%$ among those who participated in sports for 9 to 11 years, $17.9 \%$ among those who participated in sports for 12 to 14 years and $20.1 \%$ among those who participated in sports for 15 years or more. Based on the results of the chi-square test, there was a significant relationship between the number of years the athletes participated in sports and the prevalence of flat foot $\left(\chi_{(2)}^{2}=6.042, \mathrm{p}<.05\right)$. The prevalence of flat foot increased as the years spent in sports increased (Table 3).

The prevalence of flat foot based on gender was $11.7 \%$ among female athletes and $13.4 \%$ among male athletes (Table 4). No statistically significant relationship was found between the athletes' gender and the prevalence of flat foot $\left(\chi_{(1)}^{2}=.056, \mathrm{p}>.05\right)$, that is, the gender variable had no impact on the prevalence of flat foot (Table 4).

The prevalences of flat foot based on the branch of sports were as followings: $22 \%$ among freestyle wrestlers, 18\% among Greco-Roman style wrestlers, 19\% among judo players, $16 \%$ among boxers, $13 \%$ among taekwondo and handball players, $12 \%$ among swimmers, $9 \%$ among basketball players, $7 \%$ among volleyball players and $6 \%$ among soccer players. No flat foot was detected among race-walkers. A statistically significant relationship was established between the branch of sports and the prevalence of flat foot $\left(\chi_{(1)}^{2}=13.342, \mathrm{p}<.05\right)$ (Table 5).

\section{Discussion}

This study was performed to determine the effects of different branches of sports on the structure of the foot in amateur athletes. The results of the study support our hypothesis that the prevalence of flat foot among amateur athletes is associated with age, time spent participating in sports and the branch of sport, but not with gender.

It is well known that structural deformities in the foot have adverse effects on the physical and mental state of individuals [26]. Athletic activities, whether amateur or professional, bear a tremendous physical burden on the locomotor system of athletes [27]. Studies have shown that intensive training begun at early ages, especially in performance sports, caused significant changes in the postures of the athletes since the musculoskeletal system has not sufficiently matured $[27,28]$. Despite the lack of consensus on the prevalence of flat foot, some authors suggested that the prevalence of flat foot decreased by age $[29,30]$. Wojtys et al. [28] reported negative effects caused 
Table 2. Prevalence of flat foot based on age.

\begin{tabular}{|c|c|c|c|c|}
\hline \multirow{2}{*}{ Age } & & \multicolumn{2}{|c|}{ Presence of Flat Foot } & \multirow{2}{*}{ Total } \\
\hline & & None & Yes & \\
\hline \multirow{2}{*}{$14-18$ years } & $\mathrm{n}$ & 545 & 44 & 589 \\
\hline & $\%$ & 92.5 & 7.5 & 100 \\
\hline \multirow{2}{*}{$19-24$ years } & $\mathrm{n}$ & 869 & 127 & 996 \\
\hline & $\%$ & 87.1 & 12.9 & 100 \\
\hline \multirow{2}{*}{$25-29$ years } & $\mathrm{n}$ & 237 & 56 & 293 \\
\hline & $\%$ & 83.8 & 16.2 & 100 \\
\hline \multirow{2}{*}{30 years and over } & $\mathrm{n}$ & 105 & 30 & 135 \\
\hline & $\%$ & 80.9 & 19.1 & 100 \\
\hline \multirow{2}{*}{ Total } & $\mathrm{n}$ & 1,756 & 257 & 2,013 \\
\hline & $\%$ & 87.2 & 12.8 & 100 \\
\hline
\end{tabular}

$\chi_{(3)}^{2}=3.133, p=.046$

Table 3. Prevalence of flat foot based on the years spent in sports.

\begin{tabular}{|c|c|c|c|c|}
\hline \multirow{2}{*}{ Age } & & \multicolumn{2}{|c|}{ Presence of Flat Foot } & \multirow{2}{*}{ Total } \\
\hline & & None & Yes & \\
\hline \multirow{2}{*}{$3-5$ years } & $\mathrm{n}$ & 413 & 28 & 441 \\
\hline & $\%$ & 93.7 & 6.3 & 100 \\
\hline \multirow{2}{*}{$6-8$ years } & $\mathrm{n}$ & 774 & 108 & 882 \\
\hline & $\%$ & 87.8 & 12.2 & 100 \\
\hline \multirow{2}{*}{$9-11$ years } & $\mathrm{n}$ & 248 & 46 & 294 \\
\hline & $\%$ & 84.4 & 15.6 & 100 \\
\hline \multirow{2}{*}{$12-14$ years } & $\mathrm{n}$ & 174 & 38 & 212 \\
\hline & $\%$ & 82.1 & 17.9 & 100 \\
\hline \multirow{2}{*}{15 years and over } & $\mathrm{n}$ & 147 & 37 & 184 \\
\hline & $\%$ & 79.9 & 20.1 & 100 \\
\hline \multirow{2}{*}{ Total } & $\mathrm{n}$ & 1,756 & 257 & 2,013 \\
\hline & $\%$ & 87.2 & 12.8 & 100 \\
\hline
\end{tabular}

$\chi_{(2)}^{2}=6.042, p=.042$

Table 4. Prevalence of flat foot based on gender.

\begin{tabular}{lllll}
\hline \multirow{2}{*}{ Gender } & & $\begin{array}{l}\text { Presence of Flat Foot } \\
\text { None }\end{array}$ & Yes & Total \\
\hline \multirow{2}{*}{ Female } & $\mathrm{n}$ & 629 & 83 & 712 \\
& $\%$ & 88.3 & 11.7 & 100 \\
Male & $\mathrm{n}$ & 1,127 & 174 & 1,301 \\
& $\%$ & 86.6 & 13.4 & 100 \\
Total & $\mathrm{n}$ & 1,756 & 257 & 2,013 \\
& $\%$ & 87.2 & 12.8 & 100 \\
\hline
\end{tabular}

$\chi_{(1)}^{2}=.056, p=.864$

by intensive training begun at early ages on the structure of the foot, whereas Aydog et al. [27] stated that intensive training of gymnasts from early ages on had no negative effects on the structure of their foot and associated this with the exercises that strengthen and flex the muscles in the foot. Similarly, Kuo and Liu [31] stated that there was no age-related variation in the structure of the foot.

However, Redmond et al.'s study revealed a u-shaped relationship between the age and structure of the foot since individuals aged over 60 years or under 18 years of age had a tendency toward a more pronated foot posture [32]. Some other studies $[25,32,33]$ also found that the structure of the foot varies with age. Therefore, age might be a confounding factor on the prevalence of flat foot in athletes. Sport-specific training and repetitive movements have been reported to have an impact on the structure of 
Table 5. Prevalence of flat foot according to the branch of sports.

\begin{tabular}{|c|c|c|c|c|}
\hline \multirow{2}{*}{ Branch of sports } & & \multicolumn{2}{|c|}{ Presence of Flat Foot } & \multirow{2}{*}{ Total } \\
\hline & & None & Yes & \\
\hline \multirow{2}{*}{ Wrestling (Freestyle) } & $\mathrm{n}$ & 223 & 71 & 327 \\
\hline & $\%$ & 68 & 22 & 100 \\
\hline \multirow{2}{*}{ Wrestling (Greco-Roman) } & $\mathrm{n}$ & 227 & 49 & 276 \\
\hline & $\%$ & 82 & 18 & 100 \\
\hline \multirow{2}{*}{ Soccer } & $\mathrm{n}$ & 244 & 15 & 259 \\
\hline & $\%$ & 94 & 6 & 100 \\
\hline \multirow{2}{*}{ Taekwondo } & $\mathrm{n}$ & 215 & 32 & 247 \\
\hline & $\%$ & 87 & 13 & 100 \\
\hline \multirow{2}{*}{ Volleyball } & $\mathrm{n}$ & 149 & 11 & 160 \\
\hline & $\%$ & 93 & 7 & 100 \\
\hline \multirow{2}{*}{ Handball } & $\mathrm{n}$ & 128 & 18 & 146 \\
\hline & $\%$ & 87 & 13 & 100 \\
\hline \multirow{2}{*}{ Swimming } & $\mathrm{n}$ & 129 & 17 & 146 \\
\hline & $\%$ & 88 & 12 & 100 \\
\hline \multirow{2}{*}{ Boxing } & $\mathrm{n}$ & 115 & 22 & 137 \\
\hline & $\%$ & 84 & 16 & 100 \\
\hline \multirow{2}{*}{ Basketball } & $\mathrm{n}$ & 122 & 12 & 134 \\
\hline & $\%$ & 91 & 9 & 100 \\
\hline \multirow{2}{*}{ Judo } & $n$ & 102 & 23 & 125 \\
\hline & $\%$ & 81 & 19 & 100 \\
\hline \multirow{2}{*}{ Race-walking } & $\mathrm{n}$ & 56 & 0 & 56 \\
\hline & $\%$ & 100 & 0 & 100 \\
\hline \multirow{2}{*}{ Total } & $n$ & 1,756 & 257 & 2,013 \\
\hline & $\%$ & 87.2 & 12.8 & 100 \\
\hline
\end{tabular}

$\chi_{(1)}^{2}=13.342, p=0.44$

the foot and to cause substandard height of the transverse arch among soccer and tennis players and flat foot among runners and alpine skiers [34]. In other words, as the years spent playing these sports and as the age of the athletes increases, the prevalence of flat foot increases as well. Incorrect or extreme loadings or trainings exert excessive and unbalanced forces on the foot [16], resulting in the weakening or strain of the muscles, tendons and ligaments in the lower extremities and thus leading to structural deformities on the foot [29]. Our findings were similar with those studies. We thought that exposure to repetitive mechanical loading over time and using inappropriate sports shoes may cause a gradual decrease in tension of the supporting ligaments and also increase joint laxity that results in flat foot. Because of the inconsistent results reported in previous studies, the degree of mechanical loading in various sports branches on the foot posture should be investigated in detail.

While some authors suggested the importance of gender on the prevalence of flat foot $[25,33]$, others [35, 36] could not establish a significant relationship between the gender and prevalence of flat foot. Our study results did not determine a relationship between gender and flat foot and were in line with these studies. The results of our study were not consistent with the study conducted by Frey [37] and Hashimoto et al. [38]. Both authors reported that women had flatter feet than men. On the other hand, Staheli et al. [25] indicated that males have flatter feet than females. The inconsistencies between these studies and our study may be due to the age, ethnicity and cultural differences of the participants and the differences between the measurement and categorization methods of flat foot.

The higher prevalence of flat foot among freestyle wrestlers in comparison to Greco-Roman performers was another finding of our study. It was interesting to find out that although the wrestlers performed various exercises to strengthen their foot and leg muscles, they had the highest prevalence of flatfoot among the athletes studied. We relate this to the sole of wrestling shoes. We believe this may be due to the fact that, the inclination between the heel and the toe of wrestling shoes is almost the same level and the insole has no orthopedic arch. Tying the shoelaces tightly around the ankles may also be another reason for flat foot since this causes pressure on the Achilles' tendon thus resulting in straining of the muscles in the lower leg and poor functionality of the tibialis posterior muscle [39, 40]. In addition, the deformities may have been caused by excessive loadbearing on the inner edge of the foot to balance the forward-shifted center of gravity due to the wrestlers' stance. Furthermore, during the pressing and pulling from the opponent, the body weight of the wrestler pushes the talus vertically toward the ground with a greater 
force, limiting the ability of the soft tissues and the joint to resist such stress and thus inferiorly displacing the talus and causing flat foot [41]. This situation is thought to lead to misalignment of the lower extremities, changes in the traction angles of the muscles and pathological loading on the lower extremities that in turn cause pain.

Considering that some athletes, such as judo and taekwondo players, do not wear shoes, flat foot and other postural deformities in these athletes may be associated with performing the sport on non-standard tatami mats or polyurethane floors with varying hardness. Mat or floor stiffness also deteriorates in time due to repetitive low or high-impact loads. All of these factors cause excessive load-bearing on the inner edge of the foot and results in flat foot.

Another interesting finding of our study was the prevalence of flat foot in swimmers. Although flat foot may be a problem and disadvantage for athletes who are involved in land sports, it is actually an advantage for swimming. As the foot is plantar flexed, it provides a larger surface area and creates high hydrodynamic forces which act mostly in the vertical direction on the water and reduce the effort required to swim and boost the speed of the swimmer by minimizing the drag [42]. We thought that swimming did not cause flat foot since there was no pressure put on the sole of the foot. On the contrary, individuals with flat foot tended towards swimming as they moved more comfortable and easily in the water than in land activities. For this reason, we may have encountered flat feet swimmers in our study.

In conclusion, the training regimes may be a reason for feet deformities in some sports. Furthermore, based on the results of our study, we can assert that age, time spent participating in sports and the branch of sport have an impact on the higher prevalence of flat foot among the competitive amateur athletes.

\section{Recommendations}

In light of our findings, we strongly recommend the modification of training programs, redesigning of wrestling and boxing shoes in particular and using shoes with arch support in warm-ups, runs and in branchspecific educational and athletic activities and competition shoes in branch-specific trainings and competitions for a healthy foot structure. As no shoes are worn in judo and taekwondo, producing the training and competition floors with standard materials that would protect the foot structure and appropriate shoe design would be the right approach.

Further detailed investigation of the subject in multidisciplinary studies is advised. Finally, in order to avoid a possible discomfort or anatomical disorder in structure of the foot, we recommend adding special exercises that strengthen the muscles, tendons and ligaments to routine training programs.

\section{Authors' Contributions}

All authors have read and approved the final version of the manuscript, and agree with the order of presentation of the authors.

\section{Source of Funding}

No financial or material support was received in conducting this research or in preparing this manuscript.

\section{Conflict of Interests}

The authors declare that they have no conflict of interests.

\section{References}

1. Mauch M, Grau S, Krauss I, Maiwald C, Horstmann T. Foot morphology of normal, underweight and overweight children. Int $J$ Obes (Lond). 2008; 32: 1068- 75. https://doi.org/10.1038/ijo.2008.52

2. Murphy DF, Connolly DA, Beynnon BD. Risk factors for lower extremity injury: a review of the literature. $\mathrm{Br} J$ Sports Med. 2003; 37: 13- 29. https://doi.org/10.1136/bjsm.37.1.13

3. Bolgla LA, Malone TR. Plantar fasciitis and the windlass mechanism: a biomechanical link to clinical practice. $J$ Athl Train. 2004; 39: 77-82

4. Rose GK, Welton EA, Marshall T. The diagnosis of flat foot in the child. $J$ Bone Joint Surg Br. 1985; 67: 71- 8 . https://doi.org/10.1302/0301-620X.67B1.3968149

5. Staheli LT. Evaluation of planovalgus foot deformities with special reference to the natural history. J Am Podiatr Med Assoc. 1987; 77: 2- 6. https://doi.org/10.7547/87507315-77-1-2

6. Rao UB, Joseph B. The influence of footwear on the prevalence of flat foot. A survey of 2300 children. J Bone Joint Surg Br. 1992; 74: 525- 7. https://doi.org/10.1302/0301-620X.74B4.1624509

7. Giallonardo LM. Clinical evaluation of foot and ankle dysfunction. Phys Ther. 1988; 68: 1850- 6 . https://doi.org/10.1093/ptj/68.12.1850

8. Kanatli U, Yetkin H, Bolukbasi S. Evaluation of the transverse metatarsal arch of the foot with gait analysis. Arch Orthop Trauma Surg. 2003; 123: 148- 50. https://doi.org/10.1007/s00402-002-0459-7

9. Inui K, Ikoma K, Imai K, Ohashi S, Maki M, Kido M, et al. Examination of the correlation between foot morphology measurements using pedography and radiographic measurements. J Foot Ankle Surg. 2017; 56: 298- 303. https://doi.org/10.1053/j.jfas.2016.10.020

10.Uzunca K, Taştekin N, Birtane M. Relationship of pain in adulttype pes planus with radiographic and pedobarographical parameters. [Article in Turkish] Romatizma. 2006; 21: 95-9.

11.Taş S, Ünlüer NÖ, Korkusuz F. Morphological and mechanical properties of plantar fascia and intrinsic foot muscles in individuals with and without flat foot. $\mathrm{J}$ Orthop Surg (Hong Kong) 2018;26:230949901880248. https://doi.org/10.1177/2309499018802482

12.Rodriguez N, Volpe RG. Clinical diagnosis and assessment of the pediatric pes planovalgus deformity. Clin Podiatr Med Surg. 2010; 27: 43-58. https://doi.org/10.1016/j.cpm.2009.08.005

13.McPoil TG, Vicenzino B, Cornwall MW, Collins N. Can foot anthropometric measurements predict dynamic plantar surface contact area? J Foot Ankle Res. 2009; 2: 28. 
https://doi.org/10.1186/1757-1146-2-28

14.Yalçın E, Kurtaran A, Akyüz M. Pes Planus: Diagnosis, Etiology and Management. [Article in Turkish] Turkiye Klinikleri J Med Sci. 2008; 28: 743-53.

15.Guido JA Jr, Werner SL. Lower-extremity ground reaction forces in collegiate baseball pitchers. J Strength Cond Res. 2012; 26: 1782-5. https://doi.org/10.1519/JSC.0b013e31824e1211

16.Hong Y, Wang SJ, Lam WK, Cheung JT. Kinetics of badminton lunges in four directions. J Appl Biomech. 2014; 30: 113-8. https://doi.org/10.1123/jab.2012-0151

17.Kaufman KR, Brodine SK, Shaffer RA, Johnson $\mathrm{CW}$, Cullison TR. The effect of foot structure and range of motion on musculoskeletal overuse injuries. Am J Sports Med. 1999; 27: 585-93. https://doi.org/10.1177/03635465990270050701

18.Queen RM, Mall NA, Nunley JA, Chuckpaiwong B. Differences in plantar loading between flat and normal feet during different athletic tasks. Gait Posture. 2009; 29: 582-6. https://doi.org/10.1016/j.gaitpost.2008.12.010

19.Queen RM, Haynes BB, HardakerWM, GarrettWEJr. Forefoot loadingduring 3 athletictasks.AmJSports Med.2007;35:630-6. https://doi.org/10.1177/0363546506295938

20.Sallis RE, Jones K, Sunshine S, Smith G, Simon L. Comparing sports injuries in men and women. Int J Sports Med. 2001; 22: 420-3. https://doi.org/10.1055/s-2001-16246

21.Ferber R, Davis IM, Williams DS 3rd. Gender differences in lower extremity mechanics during running. Clin Biomech (Bristol, Avon). 2003; 18: 350-7. https://doi.org/10.1016/S0268-0033(03)00025-1

22.Razeghi M, Batt ME. Foot type classification: a critical review of current methods. Gait Posture. 2002; 15: 282-91. https://doi.org/10.1016/S0966-6362(01)00151-5

23.Lee MS, Vanore JV, Thomas JL, Catanzariti AR, Kogler G, Kravitz SR, et al. Diagnosis and treatment of adult flatfoot. J Foot Ankle Surg. 2005; 44: 78-113. https://doi.org/10.1053/j.jfas.2004.12.001

24.Crisan S, Zaharia VD, Curta C, Irimia ED. Computer Assisted Optical Podoscope for Orthostatic Measurements. In: Vlad $\mathrm{S}$, Ciupa RV, editors. IFMBE Proceedings: International Conference on Advancements of Medicine and Health Care through Technology. Berlin: Springer; 2011. P. 226-9. https://doi.org/10.1007/978-3-642-22586-4_48

25.Staheli LT, Chew DE, Corbett M. The longitudinal arch. A survey of eight hundred and eighty-two feet in normal children and adults. J Bone Joint Surg Am. 1987; 69: 426-8. https://doi.org/10.2106/00004623-198769030-00014

26.Scott G, Menz HB, Newcombe L. Age-related differences in foot structure and function. Gait Posture. 2007; 26: 68-75. https://doi.org/10.1016/j.gaitpost.2006.07.009

27.Aydog ST, Tetik O, Demirel HA, Doral MN. Differences in sole arch indices in various sports. Br J Sports Med. 2005; 39: e5. https://doi.org/10.1136/bjsm.2003.011478

28. Wojtys EM, Ashton-Miller JA, Huston LJ, Moga PJ. The association between athletic training time and the sagittal curvature of the immature spine. Am $J$ Sports Med. 2000; 28: 490-8. https://doi.org/10.1177/03635465000280040801

29. Nurzynska D, Di Meglio F, Castaldo C, Latino F, Romano V, Miraglia R, et al. Flatfoot in children: anatomy of decision making. Ital J Anat Embryol. 2012; 117: 98-106.

30.Echarri JJ, Forriol F. The development in foot print morphology in 1851 Congolese children from urban and rural areas, and the relationship between this and wearing shoes. J Pediatr Orthop B. 2003; 12: 141-6. https://doi.org/10.1097/00009957-200303000-00012

31.Kuo Y, Liu YSF. The foot posture index between elite athletic and sedentary college students. Kinesiology. 2017; 49: 202-7. https://doi.org/10.26582/k.49.2.6

32.Redmond AC, Crane YZ, Menz HB. Normative values for the Foot Posture Index. J Foot Ankle Res. 2008; 1: 6. https://doi.org/10.1186/1757-1146-1-6

33.Ezema CI, Abaraogu UO, Okafor GO. Flat foot and associated factors among primary school children: A crosssectional study. Hong Kong Physiother J. 2014; 32: 13-20. https://doi.org/10.1016/j.hkpj.2013.05.001

34.Klingele J, Hoppeler H, Biedert R. Statistical deviations in high-performance athletes. [Article in German] Schweiz Z Sportmed. 1993; 41: 55-62.

35.Matsuda S, Demura S, Kasuga K, Sugiura H. Reliability and Sex Differences in the Foot Pressure Load Balance Test and Its Relationship to Physical Characteristics in Preschool Children. Advances in Physical Education. 2012; 2: 44-8. https://doi.org/10.4236/ape.2012.22008

36.Zifchock RA, Davis I, Hillstrom H, Song J. The effect of gender, age, and lateral dominance on arch height and arch stiffness. Foot Ankle Int. 2006; 27: 367-72. https://doi.org/10.1177/107110070602700509

37.Frey C. Foot health and shoewear for women. Clin Orthop Relat Res. 2000; 372: 32-44. https://doi.org/10.1097/00003086-200003000-00005

38. Hashimoto M, Cheng H, Hirohashi K. Evaluation of the function of the human foot in two different conditions using radiography. J Phys Ther Sci. 2004; 16: 57-64. https://doi.org/10.1589/jpts.16.57

39. Sachithanandam V, Joseph B. The influence of footwear on the prevalence of flat foot. A survey of 1846 skeletally mature persons. J Bone Joint Surg Br. 1995; 77: 254-7. https://doi.org/10.1302/0301-620X.77B2.7706341

40.Kohls-Gatzoulis J, Angel J, Singh D. Tibialis posterior dysfunction as a cause of flatfeet in elderly patients. Foot. 2004; 14: 207-9. https://doi.org/10.1016/j.foot.2004.06.003

41.Gould N. Evaluation of hyperpronation and pes planus in adults. Clin Orthop Relat Res. 1983; 181: 37-45. https://doi.org/10.1097/00003086-198312000-00007

42.Zatsiorsky VM. Biodynamics of leg movements in swimming. In: Zatsiorsky VM, editor. Biomechanics in Sports: Performance Enhancement and Injury Prevention. $1^{\text {st }}$ ed. Massachusetts: Blackwell Science Inc; 2000. P. 224-5. https://doi.org/10.1002/9780470693797 


\section{Information about the authors:}

Korkmaz M.F.; (Corresponding author); MD, Associate Professor; http://orcid.org/0000-0001-7498-6763; dr_mfatih@yahoo. com; Department of Orthopedics and Traumatology, Faculty of Medicine, Istanbul Medeniyet University; Istanbul, Turkey.

Acak M.; Associate Professor; http://orcid.org/0000-0002-2843-4843; m.acak@hotmail.com; Faculty of Sport Sciences, Inonu University; Malatya, Turkey.

Duz S.; Associate Professor; http://orcid.org/0000-0001-7611-4838; serkan.duz@inonu.edu.tr; Faculty of Sport Sciences, Inonu University; Malatya, Turkey.

Cite this article as:

Korkmaz M.F., Acak M., Duz S. The effect of sports shoes on flat foot. Pedagogy of physical culture and sports, 2020;24(2):64-71.

https://doi.org/10.15561/26649837.2020.0203

This is an Open Access article distributed under the terms of the Creative Commons Attribution License, which permits unrestricted use, distribution, and reproduction in any medium, provided the original work is properly cited (http://creativecommons.org/licenses/by/4.0/deed.en).

Received: 20.10 .2019

Accepted: 24.11.2019; Published: 30.12.2019 